\title{
What Does Social Realism Have to Offer for Research on Teacher Identity in Mathematics Education?
}

\author{
Lise Westaway ${ }^{1} \cdot$ Gabriele Kaiser $^{2,3}$ (1) $\cdot$ Mellony Graven $^{1}$
}

Received: 29 April 2019 / Accepted: 13 September 2019 / Published online: 30 October 2019

(C) The Author(s) 2019

\begin{abstract}
Research that focuses on teacher identity is gaining traction as researchers argue that teachers mediate more than mathematical knowledge and skills in the classroom. This research tends to be underpinned by a social constructionist orientation, which foregrounds epistemology over ontology. This orientation is limiting for research that wishes to understand the base conditions that enable or constrain the expression (i.e. both communication and action) of teacher identity in teaching primary mathematics. The paper suggests that this requires research that explores the interaction between structure, culture and agency in the expression of teacher identity in teaching mathematics in primary school. The study argues that a social realist orientation is of value to research on teacher identity. From this perspective, teacher identity is defined as the manner in which teachers express their roles as teachers. As the paper is primarily theoretical, the exemplification is limited to two primary school teachers' expression of only one role namely effective communicator of mathematics. It demonstrates what social realism enables, that is, not illuminated in research underpinned by a social constructionist orientation. The argument made in this paper elucidates how social realism supports a deep analysis of the structural and agential conditions that enable and constrain teacher identities.
\end{abstract}

Keywords Language of learning and teaching $\cdot$ Primary mathematics education $\cdot$ Social constructionism $\cdot$ Social realism $\cdot$ Teacher identity

\footnotetext{
Gabriele Kaiser

gabriele.kaiser@uni-hamburg.de

Lise Westaway

l.westaway@ru.ac.za

Mellony Graven

m.graven@ru.ac.za
}

Extended author information available on the last page of the article 


\section{Introduction}

Increasingly over the past 30 years, mathematics education research has attempted to look more closely at "who the teacher is". This work focuses on teacher identity and recognises that the teacher is central to understanding what happens in mathematics classrooms. It acknowledges that teachers teach more than just mathematics subject knowledge and skills, they also communicate values, beliefs and emotional responses related to mathematics and pedagogy (Grootenboer \& Ballantyne, 2010).

Notwithstanding the significance of research from a psychoanalytic perspective, the research that forms the focus of this paper is explicitly sociological. As such, the structure/ agency debate is central, suggesting that any examination of social life and identity emergence requires an understanding of the relationship between social structures and human agents (Burridge, 2010). Research that foregrounds teacher identities within the field of mathematics education tends to be situated within a social constructionist orientation. It assumes that our knowledge of self and the world comes from our interactions with people and not some "objective" reality (Berger \& Luckman, 1966). As such it conflates questions of how we know something (epistemology) with what is (ontology). It is this elision of epistemology and ontology that makes research which seeks to examine (i) the structural and cultural mechanisms that give rise to how teachers express their identities in teaching primary school mathematics and (ii) the interplay between structure and agency in the expression of teachers' identities, practically impossible. It is for this reason that the study, on which this paper is based, draws on Archer's (1995, 1996, 2000) social realist framework. This suggests that research on teacher identity, from a sociological standpoint, should move beyond the domain of the empirical, that is, that which is observed or perceived. In examining the interplay between structure, culture and agency in the expression of teachers' identities, it is necessary to delink them so as to analyse the influence of each on the other. Structure refers to institutions, positions and roles, while culture refers explicitly to the knowledge, beliefs, discourses, ideologies etc. (Archer, 1995). Social realism posits a stratified view of agency which includes the sense of self, personal identity and social identity. A social realist framework enables one to identify the structural and cultural mechanisms, and the combination of these different mechanisms in enabling and constraining teacher identities.

The research question informing this paper is: What does social realism have to offer research on teacher identity in the field of primary mathematics? While this paper is primarily theoretical, it draws on empirical data of two primary school teachers. It demonstrates what social realism enables, that is, not illuminated in research underpinned by a social constructionist orientation. The argument made in this paper elucidates how social realism supports a deep analysis of the structural and agential conditions that enable and constrain the expression of teacher identities. Drawing on Bhaskar (2008), social realism posits that in identifying the underlying mechanisms (structures), researchers can begin to understand how and why teachers express their teacher identities in particular ways, and how we can assist teachers in shifting the manner in which they express their identities as teachers of primary school mathematics.

\section{Socio-Cultural Perspectives on Teacher Identity}

Many researchers have synthesised studies on teacher identity, each providing different insights (e.g. Darragh, 2016; Lutovac \& Kaasila, 2018; Graven \& Heyd-Metzuyanim, 
2019). While all three papers consider future directions in identity research, each of the three reviews has slightly different foci. Darragh's (2016) paper focuses on the "theoretical underpinnings, research methods and definitions of identity" (p.19) identified in 188 articles found in 85 journals. The Lutovac and Kaasila (2018) analysis of 40 peerreviewed papers between 2000 and 2015 focuses on "possible future directions for research on teacher identity in mathematics" (p.759). Building on these two reviews, Graven \& Heyd-Metzuyanim (2019) conducted their systematic review of articles from 20 mathematics education journals, known for their impact factor, over the past 5 years. Their review generated 47 papers and focused on both learner and teacher identities. Like Darragh (2016), they explored the "dominant regions, focus of research, methods and perspectives used" (p.1) and identified absences in research.

All three reviews highlight that the dominant theoretical position in teacher identity research is broadly social-cultural and raise concerns about the seeming lack of research that focuses on the psychological dimensions of teacher identity research. Lutovac and Kaasila (2018) call for a theoretical perspective that balance the psychological with the social. This psycho-social approach would include both individual cognition and affect, and the experiences as collectives.

Darragh (2016), Lutovac and Kaasila (2018), and Graven \& Heyd-Metzuyanim (2019) identify the range of theoretical frameworks utilised in the field of teacher identity research. While there is a plethora of theoretical frameworks used in research on teacher identity, three dominant frameworks in the reviews are Lave and Wenger's (1991) situated learning, Wenger's (1998) community of practice (Darragh, 2016; Lutovac \& Kaasila, 2018), and Sfard and Prusak's (2005) narrative identity (Graven \& Heyd-Metzuyanim, 2019).

All three studies highlight that there are different definitions of identity within the teacher education research. While Durragh (2016) and Lutovac and Kaasila (2018) purport that identity is often ill-defined within the research on teacher identity, Graven \& Heyd-Metzuyanim (2019) maintain that recent researchers make an explicit attempt to define identity. It is not the definitions of identity that are of concern, but rather the challenge to operationalise identity (Sfard \& Prusak, 2005). They argue that conceptions of identity as performance/action/practice have not been fully operationalised as it is difficult to "see" identity in action.

To operationalise identity, Sfard and Prusak (2005) distinguish between first person narratives (the stories people tell about themselves) and third person narratives (the stories people tell about others). Identity research that is primarily based on observing teachers' actions focuses on third person narratives, whereas interviews include first person narratives. Drawing on Sfard (2006), Graven \& Heyd-Metzuyanim refer to an ontological collapse when researchers tend to conflate first person narratives with third person narratives. They noted however that "studies that adopted a discursive viewpoint usually did not have ontological collapses. They were very careful to report about the participants narratives and not make any other claims" (p. 4).

All three papers acknowledge the different conceptions of identity that are often explained in theoretically inconsistent ways (Darragh, 2016). Darragh (2016) identified five conceptions of identity: (1) identity as participative, (2) identity as narrative, (3) identity as discursive, (4) identity as psychoanalytic, and (5) identity as performative. Darragh (2016) positions herself within the identity as performative conception and argues that identity "exists in the moment of the performance and as it is recognised. We perform ourselves - be it by telling stories, joining groups, acting in a particular 
way at a particular time, positioning ourselves and others within wider societal discourses ... identities are performative, we act them into being (Butler, 1988)" (p.29).

These conceptions of teacher identity are not isolated. Within the description of identity as performative, there is evidence of identity as participative ("joining groups"), identity as discursive ("positioning ourselves and others within wider societal discourses"), and identity as narrative ("by telling stories"). As such, it appears that researchers may ascribe themselves to more than one of Darragh's identified conceptions of identity.

Lutovac and Kaasila (2018) and Graven \& Heyd-Metzuyanim (2019) make suggestions for future research on teacher identity. Lutovac and Kaasila (2018) argue for a balance between the individual and social and a link between mathematics education research and general education research on teacher identity. Graven \& HeydMetzuyanim (2019) call for research that links identity with mathematical objects in order to make identity research relevant to the mathematics taught and learned in the classroom. Furthermore, they suggest that research on identity should examine more closely the relationship between teacher and learner identities.

All three of these reviews are based on articles that are predominantly from countries outside of Africa. Evident in a survey on identity research within the field of mathematics education in South Africa and published in South African journals accredited by the Department of Higher Education and Training, is a view that identities are dynamic and contingent (Westaway, 2017). Based on the analysis of the aforementioned research within the field of mathematics education, teacher identity can be categorised in accordance with four broad perspectives: (1) identity as being recognised as a certain kind of person (Pausigere, 2014), (2) identity as narrative (Graven, 2012), (3) identity as learning (Graven, 2012; Nel, 2012; Pausigere \& Graven, 2013), and (4) identity as pedagogically prescribed (Jansen, 2001; Graven, 2012; Naidoo \& Parker, 2005; Jita \& Vandeyar, 2006; Pausigere \& Graven, 2013). The dominant conceptions in research published in these journals are framed theoretically by Lave and Wenger (1991) and Wenger (1998) and Bernstein's (2000) pedagogical identity. As such, there is some synergy between the South African and international identity research.

Identity as being recognised as a certain kind of person is evident in both the research on teacher identity generally and within mathematics education specifically. Grootenboer, Smith and Lowrie (2006) suggest "how individuals know and name themselves and how an individual is recognised and looked upon by others" (p. 612) reflects their identity. With teachers who are not subject specialists, Pausigere (2014) proposes that primary mathematics teacher identity is "a way of talking about who primary mathematics teachers are and how they name themselves and how they are recognised by others with respect to the subject of mathematics and its corresponding activities" (p. 6). This perspective thus posits that teacher identity is about performativity, in other words, what teachers say and do in the classroom, school and community.

Identity as a narrative draws prominently on the work of Sfard and Prusak (2005). Rather than viewing identities as representations of narratives (Drake \& Sherin, 2006), they "equate identities with stories about persons" (p.14). Their description of identity relates to a concern of how to operationalise identity in research. Graven 2012 reinterpreted data, which she initially analysed and explained using Lave and Wenger (1991) and Wenger (1998), by drawing on the work of Sfard and Prusak (2005). She maintained that Sfrad and Prusak (2005) "explicitly highlight that their definition 
presents identities as discursive counterparts of lived experiences, whereas Wenger (1998, p. 151) sees such words as only part of 'the full, lived experience of engagement in practice" (Graven, 2012, p.130). Working with mathematical literacy teachers, Graven, 2012 showed how participation in a professional community could promote a change in actual ("current") and designated identities. In the South African educational context where teachers are often described as "deficit" (having insufficient content knowledge and poor pedagogical practices), participation in a professional community led to teachers valuing their teaching experiences and knowledge, participating in other professional activities, becoming lead teachers and talking about themselves as life-long learners.

Identity as learning is viewed as embedded in professional learning communities. Learning in this context is described by Lave and Wenger (1991) as a process of participation in social practices rather than the individual acquisition of knowledge. Engagement in social practices within communities of practice gives learning a context, and the learners, in the process, develop their social identities. In this sense, "learning and a sense of identity are inseparable: they are aspects of the same phenomenon" (Lave \& Wenger, 1991, p. 115). This conception of identity is particularly prevalent within the realm of teacher education. Research situated within this discourse illuminates how participation in CoP can alter teachers' sense of belonging and strengthen their mathematics teacher identities (Graven, 2003; Nel, 2012; Pausigere, 2014).

Identity as pedagogically prescribed has its roots in Bernstein's (2000) work on official pedagogic identities. Bernstein (2000) makes a distinction between identities as endorsed and communicated through policy and how teachers (inter)act with such policy. A number of researchers have explored official pedagogic identities particularly in relation to reform curricula (e.g. Pausigere \& Graven, 2013). Within such a teacher identity perspective, the official pedagogic identities as discourses have the potential to act on and produce teachers' identities, their teaching of mathematics and the learners' experiences of this teaching, which in turn produces the way in which teachers and learners recognise themselves.

While each of these four perspectives provide different explanations of teacher identity, common to all of them is that they support a social constructionist agenda. As such, these perspectives give primacy to discourse, primarily viewed as language, in the construction of teacher identity, and foreground epistemology over ontology.

\section{Critique of Social Constructionist Conceptions of Identity}

Social constructionism suggests it is in communication with people that our knowledge of self and society is produced (Berger \& Luckman, 1966). While identity as being a certain kind of person, identity as narrative and identity as learning all emphasise the communicational process in the construction of identity, MacLure (2003) suggest that identity as discursive requires that one "suspends your belief in the innocence of words and the transparency of language as a window on an objectively graspable reality" ( $\mathrm{p}$. 12). In other words, he maintains that language is neither neutral, nor does it reflect an objective reality. Archer (1995) criticises these perspectives for their possible restraint in moving beyond the realm of discourse. In adopting a realist social ontology, she suggests that human beings not only have discursive relations to the world, but also practical and embodied relations. In contradistinction to social constructionism, social 
realism gives primacy to practice rather than discourse in the expression of teachers' identities. It is through our actions (or practices) that identities of self and other(s) become specified. What this means is that "language is not the 'great divide', for there is a genuine primacy of practice which yields reasoned knowledge non-discursively" (Archer, 2000, p. 151). Archer (1996) thus maintains that while language is acquired through practice, it also initiates new practices. As such, language has tendential powers that enable and/or constrains the practices of teachers.

Identity perspectives underpinned by social constructionism assume that research does not describe a prior reality, but rather that it constructs reality (Foucault, 1982). This perspective assumes a flat ontology and limits reality to the empirical domain (Elder-Vass, 2008). Put differently, reality correlates with people's perceptions and experiences of it. A flat ontology thus ignores the existence of a reality independent of our knowledge of it. Bhaskar (2008) refers to this as the "epistemic fallacy", that is, privileging questions of how we know something over what is. In contrast to a social constructionist view of reality, Bhaskar (2008) and Archer (1995) posit a stratified view of reality whereby our experiences and perceptions constitute only one aspect of reality. For them, social structures exist and are causally efficacious (Bhaskar, 2008). For example, beliefs are real as they have effects. The belief that "mathematics is not for everyone" has effects on teachers" practices in the classroom.

A non-dualistic process ontology, also evident in social constructionist research especially from an identity as learning perspective, offers an inseparability thesis. Put differently, it presumes that what is internal to the person cannot be separated from what is external to the person. It posits that only processes are "real", that is, the interactions between individuals that occur in space and time. Social systems and structures are deemed not real, they are virtual, and called into being through the interactions of agents (Giddens, 1984). Central to this view of ontology is the "fallacy of conflation", that is, the merging of structure and agency (Archer, 1995), where structure and agency are viewed as mutually constitutive.

Notwithstanding the significance of a social constructionist theorisation of teacher identity, it appears to restrict opportunities to examine the structural and agential conditions, and the interplay between these conditions, that give rise to the expression of teachers' identities in primary school mathematics. As such, a social constructionist theorisation of teacher identity appears insufficient for research that seeks to examine the base conditions that enable and/or constrain teacher identities. These perceived limitations led to a search for a different orientation for researching teacher identity. Archer's social realism, and particularly her morphogenetic approach, provides the methodological tools necessary to delink structure and agency for methodological purposes in order to examine their interplay.

\section{Social Realism as an Alternative Framework for Research on Teacher Identity}

Social realism is under-laboured by a critical realist philosophy. Critical realism postulates that reality exists independent of our knowledge of it, but our knowledge of the world is fallible and thus always open to review (Bhaskar, 2008). Social realism draws on the critical realist concepts of depth ontology, analytic dualism and temporality. The notion of a depth ontology is suited to research that wishes to understand the base conditions of a phenomenon. Reality is stratified in that it consists of three 
domains. The domain of the empirical consists of people's subjective perceptions and experiences of what occurs in the world, while the domain of the actual comprises the objective world of events that give rise to people's perceptions and experiences. The domain of the real includes experiences, events and the structures that exist in the world irrespective of whether they generate events or not (Bhaskar, 2008). For example, in the mathematics classroom, the teaching of mathematics would be an event (domain of the actual). The experiences of learners and the teacher of that event are part of the empirical domain. The mechanisms that enable or constrain the teaching of mathematics are base conditions in the domain of the real.

In order to examine the interplay between structure, culture and agency, Bhaskar (2008) and Archer (1995) maintain that it is necessary to assign independence to each. Structure, culture and agency are viewed as autonomous, and ontologically and temporally distinct as they each have properties and powers that impact on the other. Structures refer to institutions, roles and positions, while agency is based on a stratified view of persons (i.e. self, personal identity and social identity) (Archer, 2000). Archer separates structure from culture arguing that cultural mechanisms are ideational and include discourses, ideas, concepts and beliefs. Archer refers to these mechanisms as "intelligiblia" (Archer, 1996). The discipline of mathematics is an example of such "intelligiblia". It is a discursive product of human (inter)action. Such social products exist in the world; they are real and, as such, have effects (Fleetwood, 2014). Mathematics is thus a causal mechanism not in the human sense of constant conjunctions (Bhaskar, 2008), but rather, tendentially. In other words, a critical realist position is not the same as naïve realism, which posits a platonic view of mathematics as a discipline.

Analytical dualism suggests that people and structural mechanisms are ontologically distinct and have properties and powers that are irreducible to each other (Archer, 1995). It is through the separation of structure and agency, for methodological purposes, that the interplay between the individual and the social in the expression of teachers' identities can be identified. This concept enables researchers to move beyond conflationary theorising evident in social constructionist research.

Temporality is fundamental to the social realist thesis. Archer (1995) argues that "(i) structure necessarily predate the action(s) of agents that transform it; and (ii) that structure necessarily postdates those actions" (Archer, 1995, p.168). The manner in which teachers mediate structures, that is, teacher agency, plays a role in the expression of their teacher identities. This enables researchers to explain why teachers with similar life experiences act differently in the classroom.

\section{Archer's Morphogenetic Approach}

Archer's (1995) Morphogenetic Approach provides the methodological tools to delink structure, culture and agency in order to investigate the interplay between them over time and explain how and why teachers' practices change or remain the same. Drawing on an example from empirical data, Fig. 1 demonstrates the Morphogenetic Approach over four timescales while at the same time reflecting the three domains of reality.

Time 1 (T1) in Fig. 1 refers to the structural (e.g. policies) and cultural (e.g. beliefs) mechanisms that condition the (inter)actions of agents. These mechanisms which are part of the domain of the real are always historically situated and conditioned. How people respond to the constraining or enabling structural and cultural contexts they 


\begin{tabular}{|c|c|c|c|}
\hline Time 1 (T1) & \multicolumn{2}{|c|}{ Time 2 - Time 3 (T2-T3) } & Time 4 (T4) \\
\hline $\begin{array}{l}\text { Structural and cultural } \\
\text { mechanisms (e.g. curriculum) } \\
\text { Cultural mechanisms (e.g. } \\
\text { beliefs) }\end{array}$ & \multicolumn{2}{|c|}{$\begin{array}{l}\text { (Inter)action between } \\
\text { teachers and learners (the } \\
\text { expression of teachers' } \\
\text { identities in teaching primary } \\
\text { school mathematics) }\end{array}$} & $\begin{array}{l}\text { Structural and cultural } \\
\text { mechanisms (e.g. curriculum) } \\
\text { Teacher identities } \\
\text { Cultural mechanisms (e.g. } \\
\text { beliefs) }\end{array}$ \\
\hline \multirow[t]{2}{*}{$\begin{array}{l}\text { Real: Cultural and } \\
\text { structural mechanisms } \\
\text { condition teachers' identities }\end{array}$} & \multirow{2}{*}{$\begin{array}{l}\quad \text { Actual: } \\
\text { Expressing her } \\
\text { teacher identity } \\
\text { in teaching } \\
\text { Grade } 3 \\
\text { mathematics }\end{array}$} & \multirow[t]{2}{*}{$\begin{array}{l}\text { Empirical: } \\
\text { Children and } \\
\text { teachers' } \\
\text { experiences of } \\
\text { the event }\end{array}$} & $\begin{array}{l}\text { Morphostasis: Structural } \\
\text { and cultural mechanisms and } \\
\text { teachers' identities remain } \\
\text { unchanged }\end{array}$ \\
\hline & & & $\begin{array}{l}\text { Morphogenesis: } \\
\text { Structural and cultural } \\
\text { mechanisms and teachers' } \\
\text { identities remain unchanged }\end{array}$ \\
\hline
\end{tabular}

Fig. 1 An adaptation of Archer's (1995) Morphogenetic Approach for interpreting primary school mathematics teaching (adapted from Westaway \& Graven, 2018)

have inherited, is the focus of Time 2 (T2) to Time 3 (T3). In Fig. 1, this is represented as the (inter)action between the teacher and learners in the mathematics lesson. T2 to T3 represents both the domains of the actual and empirical. If the effect of agential (inter)action (i.e. between the teacher and learners) is morphogenesis, then it is probable that this would result in an elaboration of the structure (e.g. curriculum), culture (e.g. beliefs) and the agent at Time 4 (T4). T4 becomes the new T1 of the next morphogenetic cycle with its conditioning effects on future (inter)actions (Archer, 1995, 1996). In relation to the morphogenetic cycle, agential reflexive deliberations play a mediatory role between structure, culture and agency because it is only through the projects of individuals (e.g. teaching) that structural and cultural enablements and constraints are activated.

This paper argues that social realism has much to offer research that seeks to examine the roles that structure, culture and agency play in the expression of teachers' identities in the teaching of mathematics.

\section{A Social Realist Conception of Identity}

Archer's (2000) conception of identity is embedded within a notion of agency. In other words, developing an understanding of agency and the morphogenesis of agency from a social realist perspective presupposes a particular understanding of identity. Unlike social constructionism, Archer (2000) proposes a stratified view of persons each with their own properties and powers emerging from four levels, that is, the self, the person (personal identity), and the agent and actor (social identity). Each of these aspects of individuals develop as they engage in the natural, practical and social worlds (Archer, 2007).

A continuous sense of self enables individuals to know themselves over time. It develops first and foremost through practice, as opposed to a concept of self which is 
social and discursive (Archer, 2000). The argument for the centrality of practice implies that central to the emergence of self is first, "doings" as opposed to "meanings". This is a challenge to social constructionism, which reifies language, "making epistemology prior to ontology" (Archer, 2000, p. 189) and eliding "the concept of self with the sense of self" (Archer, 2007, p.12). In this sense, language is a practical activity. Our words are "deeds" and in relation to the emergence of our sense of self are not hegemonic (Archer, 2000).

The emergence of personal identity from self depends on what we care about in the world. In establishing our ultimate concerns (what we care about most at a particular point in time), we define our personal identities. Discerning our ultimate concerns from the range of possible concerns depends upon the activity of reflexivity, that is, individuals' capability "to consider themselves in relation to their (social) contexts and vice versa" (Archer, 2007, p. 3).

The development of social identity involves a double morphogenesis where agency, while leading to structural and cultural elaboration (or reproduction), is itself elaborated (or reproduced). In other words, the same event that brings about structural and cultural change has the potential to also bring about systematic change of agency. Social identity emerges at the intersection of structure, culture and agency (Archer, 2000).

"It is therefore necessarily relational, and for it to be properly so, then independent properties and powers have to be granted to both 'structures' and to 'agents'. This is what is distinctive about the social realist approach. It grants the existence of people's emergent properties (PEPs) and also the reality of structural and cultural emergent properties (SEPs and CEPs) and sees the development of agents and actors as relational developments occurring between them" (Archer, 2000, p.255).

Emerging from this intersection are the concepts of agent and actor, both accounting for our social identities.

"Agents are defined as collectives sharing the same life-chances ... By contrast, it is only social Actors who properly exist in the singular and who alone meet the strict criteria for possessing unique identity" (Archer, 2000, p.261). Actors occupy various social roles. They are regarded as "role incumbents ... roles themselves have emergent properties which cannot be reduced to the characteristics of their occupants" (Archer, 2000, p.283).

In other words, social roles pre-exist the occupants of such roles, and these have the power to constrain and enable the (inter)actions of agents. The expression of our concerns in our social roles and the manner in which we do this refers to our social identity (Archer, 2007). While people have multiple social roles, this paper focuses specifically on the roles of teachers. Teacher identity is therefore regarded as the manner in which teachers express their roles as teachers.

\section{Design of the Study and Methodological Issues}

\section{Research Design}

This research formed part of a larger national study funded through the European Union and referred to as the European Union: Strengthening Foundation Phase Teaching and Teacher Education project. Sixty schools were chosen to be representative of 
the majority of primary schools in the Eastern Cape in South Africa. By that, we mean they are in low socio-economic communities and charge no fees and the Language of Learning and Teaching (LoLT) is isiXhosa for the first 3 years of formal schooling. During this time, English is taught as an additional language. Despite English being taught as an additional language, learners are expected to learn mathematics and other subjects in English from grade 4.

The empirical field of study covered four primary school teachers at two schools in Lwandle Township, an area historically designated for black South Africans, and which is still populated by black South Africans today. All four teachers were female, isiXhosa Home Language speakers and between the ages of 39 and 55 at the time of the research. The two teachers in this article represent contrasting examples in that the one teacher is a proponent of learning in the LoLT, while the other favours English.

The research adopted a qualitative case study methodology, which is particularly useful in studying a complex phenomenon such as teaching in-depth and comprehensively, in order to ascertain "why things are as they are" (Easton, 2010, p.119). It enables the examination of the phenomenon of teacher identities in teaching mathematics in the primary school in complex contexts (social, economic, etc.). The intensive nature of case study research assists in teasing out complex relationships during the research process. Case study was particularly useful as "people act within this stratified world, whose complex mediation of what they do results in social action having all sorts of unintended consequences - and generating further emergent features and properties - which in turn help to shape the social environment for subsequent actors" (Carter \& Sealey, 2000, p.16).

The case study methodology not only enabled the identification of similarities and differences (organised into themes), it also allowed for comparison across the teachers and enabled comparison with other research on teacher identity. More importantly, the case study enabled the surfacing of tendential structural and cultural mechanisms.

\section{Methodological Implications}

The first author spent 4 weeks with each of the teachers, observing their mathematics lessons, and interviewing them about their life histories (LHI), mathematics histories (MHI) and mathematics teaching practices (PI). All the interviews were conducted in English and transcribed immediately after they had taken place. The observations were written as field notes and three mathematics lessons per teacher were video-recorded. Given that the LoLT was isiXhosa, a First Language isiXhosa speaker transcribed and translated the data. The field notes were initially written in a combination of English and isiXhosa. The first author has some competence in reading and writing isiXhosa.

Data analysis was initially done through coding and categorising the data according to themes. This was based on similarities and differences that emerged from the data. As the empirical exemplification of this paper focuses on the teachers' expression of the role of communicator of mathematics, we provide excerpt 1 as an example of the language used in Buhle's class to teaching multiplication, and excerpt 2 to provide an example of codes related to the category of language from Nokhaya's MHI. In excerpt 1 , the isiXhosa transcription (see italicised words) shows the extent to which the teacher, Buhle, uses English in teaching mathematics. 
Excerpt 1 The extent to which English is used by Buhle in teaching mathematics

\section{isiXhosa transcription}

11. Buhle Five phinda-phinda ngo two. Five times two. Oo-five ababini asidibanisi. Sibusiso?

12. L Ten

13. Buhle Uright uSibusiso?

14. LL Yes

15. Buhle Five times two? Oo-five abangaphi? Ababini. [She counts in English] One, two, three, four, five. [She puts a circle them.] Naba oo-five bakho bayi two. Five times two.

\section{English translation}

Five times two. Five times two. Two fives. We are not adding. Sibusiso?

Ten

Is Sibusiso correct?

Yes

Five times two? How many fives? Two. [She counts in English] One, two, three, four, five. [She circles them.] Here are your fives; there are two of them. Five times two.

In excerpt 2, Nokhaya expresses concerns about the LoLT in grades 3 and 4, and the view that code-switching in grade 3 would assist learners with the change from grade 3 to 4 and in developing their mathematics understanding. These codes all relate to the category of language.

Excerpt 2 An example of a language concern as expressed in Nokhaya's MHI

\begin{tabular}{|c|c|c|c|}
\hline & & isiXhosa transcription & Coding \\
\hline 118. & Nokhaya & $\begin{array}{l}\text { We work closely but the problem is these kids are doing } \\
\text { maths in Xhosa now and when they come to Grade } \\
\text { four there's a new language. Here we talk about } \\
\text { 'amaphezulu' and when they go to Grade four, they } \\
\text { will be talking about 'fractions' and that's typically } \\
\text { confusing because they will be new words to them. }\end{array}$ & $\begin{array}{l}\text { Shift from learning in } \\
\text { isiXhosa to English }\end{array}$ \\
\hline 119. & Lise & $\begin{array}{l}\text { Now do the teachers code switch in grade 4. Do they } \\
\text { speak isiXhosa and English? }\end{array}$ & \\
\hline 120. & Nokhaya & $\begin{array}{l}\text { I do not know, but I think they coach because the kids } \\
\text { would not understand }\end{array}$ & $\begin{array}{l}\text { The relationship between } \\
\text { language and } \\
\text { understanding }\end{array}$ \\
\hline 121. & Lise & I would imagine they would have to use the isiXhosa & \\
\hline 122. & Nokhaya & $\begin{array}{l}\text { But if we make English and isiXhosa in grade 3, the kids } \\
\text { will understand better, but our question papers } \\
\text { encourage us to only use isiXhosa. }\end{array}$ & $\begin{array}{l}\text { Code-switching between } \\
\text { isiXhosa and English }\end{array}$ \\
\hline
\end{tabular}

However, this only gave access to the empirical domain, that is, the teachers' and researcher's experience and perceptions reflected in their LHI, MHI, PI and mathematics lessons. In order to identify the more general structures from the interview and observation data, two thought processes that are commonly used in critical realist research were used: abduction and retroduction. Abduction refers to the process of redescribing an observation or concrete event using a different frame of interpretation, that is, social realism (Danermark, Ekström, Jakobsen, \& Karlsson, 2002).

Retroduction is the process of transfactual argumentation where the researcher moves beyond the empirical to understand the prerequisites of a phenomenon (Danermark, Ekström, Jakobsen, \& Karlsson, 2002). This is achieved by asking transfactual questions that is questions that require "looking back". In reading through the video transcripts and field notes, it was evident that the teachers differed in the language they used to teach mathematics. Questions, such as, what do these 
communication practices presume? assisted in identifying the structural, cultural and agential conditions that enable or constrain the way in which the teachers' expresses their roles as primary school mathematics teachers.

\section{Empirical Exemplification}

The two teachers chosen for exemplification of what social realism enables researchers to do are Nokhaya and Buhle (pseudonyms). Due to scope, we have chosen to focus on only one role, that is, "effective communicator of mathematics". A social realist analysis of additional data can be found in Westaway \& Graven 2018 and Westaway, 2019. The examples chosen for the empirical exemplification in this article, represent a general concern that primary school teachers express, namely which language to teach mathematics in. While they are expected to teach in isiXhosa, the home language of the learners, some teachers are concerned that this poses challenges for learners when English becomes the LoLT. The examples show the various mechanisms that condition the teachers' practices, those that are similar and different.

\section{Social Realism and the Expression of Teachers' Identities}

Archer (1995) explains that: "Given their pre-existence, structural and cultural emergent properties shape the social environment to be inhabited. These results of past actions are deposited in the form of current situations. They account for ... the nature of the extant role array, the proportion of positions available at any time and the advantages/ disadvantages associated with them ... In these ways, situations are objectively defined for their subsequent occupants or incumbents" (p. 201).

As noted above, teacher identity refers to the expression of our roles as teachers. According to the Norms and Standards for Educators in South Africa (SA.DoE, 2000), being able to communicate effectively is a key aspect of the teachers' role as learning mediator. This policy document reads as follows:

"The educator will mediate learning in a manner which is sensitive to the diverse needs of learners, including those with barriers to learning; construct learning environments that are appropriately contextualised and inspirational; communicate effectively (italics added), showing recognition of and respect for the differences of others" (p. 13).

Communicating effectively for Nokhaya and Buhle involves making decisions in the classroom about the LoLT necessary to give clear explanations. While both Nokhaya and Buhle hold that it is the teachers' role to explain mathematical concepts clearly to the children in their class, the language they choose to do this in differs. Nokhaya teaches in isiXhosa, whereas Buhle uses isiXhosa and English interchangeably.

In terms of government policy, teachers are required to use the LoLT "appropriately to explain, describe and discuss key concepts in the particular subject" (SA.DoE, 2000, p.16). While the LoLT in both schools was isiXhosa, teachers differed in their opinions as to whether this was the appropriate language for learning mathematics. The Language in Education Policy (SA.DoE, 1997) states "the right to choose a language of learning and teaching is vested with the individual" (meaning parent or caregiver) (p. 1). However, the South African Schools Act (SA.DoE, 1996) gives School Governing Bodies the right to choose the LoLT in schools. Presently, in South Africa, the first 3 years of formal schooling should be taught in the home language of the child. With 
the home language of over $70 \%$ of people in Lwandle being isiXhosa, it is not surprising therefore that the LoLT in the early years of primary school is isiXhosa.

Nokhaya expresses her teacher identity by teaching mathematics in isiXhosa. When the children speak in English, she asks them to revert to isiXhosa. In a lesson on addition of two three-digit numbers, Nokhaya asks the children to read the answer to an addition sum that has been calculated. The class say "three hundred and five" to which she immediately responds "No, you are using English" (Nokhaya, VRL 1, tt.91-92). During the first practice interview, I ask her why she wants the children to speak solely in isiXhosa in the mathematics lessons. She explained, "I want them to master their language in so much that I encourage them not to use any English words when we are doing Maths and isiXhosa. ... So that they can like their language" (Nokhaya, MTPI 1, t.24).

In an attempt to provide clear explanations, Buhle chose to use both isiXhosa and English, despite the LoLT in the early years of primary school being isiXhosa. Terminology is given to the children in both isiXhosa and English. Knowing that children are expected to learn in English from grade 4 was a cause for concern for Buhle. She articulated this tension, when she explained why her children count in isiXhosa despite them counting in English in their everyday lives.

"The curriculum says that when we count, we must count in our language. But it's difficult for them. ... We teach them our language how to count in our language. But the problem is ... when they go to ... the [higher primary school], they won't say 'nye' ('one') anymore. And they don't understand how to count in our language and even to write it. They can count, but they can't write it" (P1, t.14).

Buhle thus uses a combination of isiXhosa and English in her class. For example, the children count in ones in isiXhosa and for the rest they use English. Not surprisingly then, Buhle's class was not sure of the isiXhosa number names after 100. In a lesson on addition of two three-digit numbers, Buhle has two sums written on a chart that she asks the children to read. The first sum is " $239+156$ ". The field notes record the unfolding events as follows: "Buhle takes a pointer ... She asks the children to read it. She has to help them as they are not very sure of the isiXhosa number names for ' 239 ' and '156"' (Buhle, FN, p. 6).

In many instances, English appears to be the default language in Buhle's class as she appears to "naturally" communicate number words and mathematical terms in English in her lessons. For example, in excerpt 1, Buhle translates mathematics terminology into English. In her lesson on multiplication, she uses the terms "phinda-phinda" (isiXhosa) and "times" (English) interchangeably. However, when she asks the children to calculate, she generally uses the term "times", for example, "five times ten" rather than "five phinda-phinda ngo-ten" or "uzintlanu umphinda-phinda ngolishumi".

Teaching almost solely in isiXhosa is not without its complications. Both Nokhaya and Buhle described some challenges with the use of isiXhosa in the Annual National Assessments (ANA) and the National Workbooks. Nokhaya complained, "If they were using the words that are too close to English like "ihafu" ("half") instead of "isiqingatha" ("half"), they would understand it. But they use the more difficult words in Xhosa" (MHI, t.126). Likewise, the National Workbooks use terms that are not used colloquially in isiXhosa or that children are familiar with. At home, children typically use English when referring to numbers, telling the time etc. English thus seems to be the "default language" in mathematics lessons for many children, which is why Nokhaya has to repeatedly remind them not to speak English. 
Nokhaya's choice of language to communicate mathematics is conditioned by, amongst other things, the value she places on isiXhosa. She regards it as important for children to learn their language. She is proud of her first language and wants her children to share this pride. Her sense of self is inextricably intertwined with her being a first language isiXhosa speaker. By contrast, Buhle is concerned that the grade 4 teachers (who will teach maths in English) will judge her if her children cannot do mathematics. "I will be happy if there are a few children that can show the Grade 4 teachers that I did teach them maths" (Buhle, MHI, t.134). This, together with the shift between learning in isiXhosa in grade 3 and English in grade 4, is of great concern to her. The complexity of language in schools where children transition from learning in their home language to learning in an additional language at the end of grade 3, cannot go unrecognised, as the implications for communicating mathematics concepts clearly are significant.

An added complication is that while the policies advise that teachers teach in isiXhosa, many parents would prefer their children to learn in English because of the access this provides to social and economic power (Setati, 2008). Since language is political, such access to "social goods" often takes priority over epistemological access (Setati, 2008; Phakeng \& Moschkovich, 2013). Alexander (2013) argues that "we have to change radically the inherited linguistic habitus in terms of which English is the only feasible candidate for language of high status" (p. 76).

While both Nokhaya and Buhle suggested that one of their roles is that of effective communicator, the research has shown that this is complicated by the decisions they have to make with regard to which language to use to teach mathematics.

The structural and cultural mechanisms conditioning the expression of Nokhaya and Buhle's wish to provide clear mathematical explanations for their learners are conditioned by: (1) the Language Policy in South Africa, (2) the change in LoLT from grade 3 to grade 4, (3) the national workbooks and ANA, (4) the language that the children use when counting, and so forth, in their everyday lives, and (5) the various isiXhosa dialects.

\section{The Relationship Between Structure, Culture and Agency}

Figure 2 below provides a synopsis of the structural and cultural mechanisms that constrain and enable the manner in which Nokhaya and Buhle express the systemic role of a learner mediator, particularly in relation to effective communication. It is based on the transfactual question-What does the manner in which Nokhaya and Buhle perform their roles as effective communicators presume? This is a question that requires "looking back" in order to identify the mechanisms at the level of the real. Bhaskar's (2008) depth ontology is useful in understanding Fig. 2. "The extent to which the teachers communicate effectively" is part of the empirical domain. Ascertaining this, would be based on the perceptions of the learners, the teacher and the researcher. The level of the actual is the manner in which Nokhaya and Buhle communicate in their mathematics lessons, in other words, how they express their teacher identities. Nokhaya uses isiXhosa, while Buhle uses a combination of isiXhosa and English. The rest of the diagram signifies the real, that is, the structural and cultural, mechanism giving rise to the language choices teachers make in the mathematics classroom.

In Fig. 2, it is evident that the LoLT structures both teachers' choice of language in which to communicate mathematical concepts. 


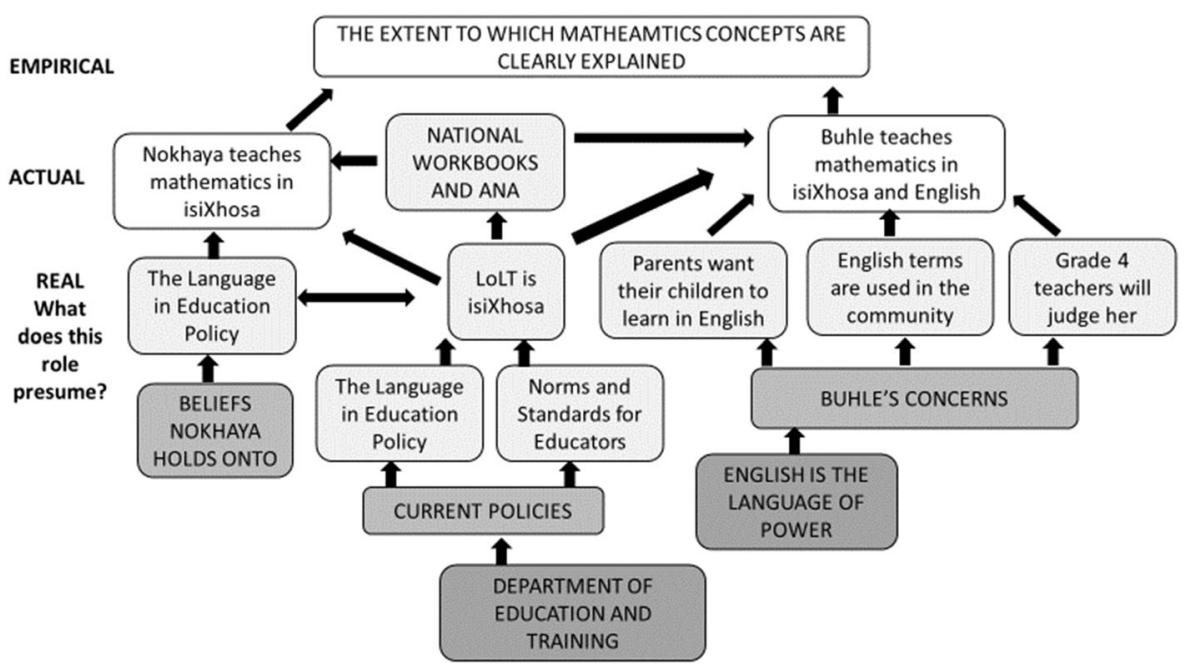

Fig. 2 The expression of Nokhaya and Buhle's teacher of mathematics identities

The ANA and the National Workbooks are all in isiXhosa. The LoLT is based on two policies, the Language in Education Policy and the Norms and Standards for Educators in South Africa. These two polices were developed in consultation with the Department of Basic Education. Buhle's role as an agent comes to the fore in her decision to use English, in addition to isiXhosa. This is enabled by the fact that children encounter and use mathematics terms in English in their environment, and her fear that the grade 4 teachers may judge her if her learners do not know the English terms. These enablements are supported by the majority of South African parents wanting their children to learn in English because English is viewed as the language of power. Nokhaya, by contrast, chooses to teach solely in isiXhosa as the expectation in the Language Policy is synchronous with her belief that children need to learn to appreciate their own language.

\section{Discussion and Conclusion}

Earlier in this paper, four perspectives emerging from socio-cultural research on teacher identity within the field of mathematics education in South Africa were identified. These included the following: identity as being recognised as a particular kind of person, identity as narrative, identity as learning and identity as pedagogically prescribed. Each of these perspectives is underpinned by social constructionism which suggests that reality is equated with epistemology (i.e. what we know), and what is internal to the person cannot be separated from what is external to the person (i.e. the conflation of structure and agency). While this paper acknowledges the importance of research on teacher identity underpinned by a social constructionist orientation, it has argued that this perspective is not suited to all socio-cultural research with a focus on teacher identity. As Cobb (cited in Lester, 2005) explains, it is important to compare theoretical perspectives in terms of how they orientate the research and the kinds of questions asked.

The question this paper has focused on is: What does social realism have to offer research on teacher identity in the field of primary mathematics? It is based on research 
that focused on how the interplay between structural, cultural and agential mechanism give rise to the expression of teachers' identities in primary school mathematics. Research that wishes to identify the underlying conditions that give rise to teachers' identities requires a methodological framework that makes three key assumptions. Firstly, that structural and cultural mechanisms exist prior to teachers and that teachers' identities are conditioned by these mechanisms. Secondly, that reality is differentiated and stratified as it is the structural and cultural mechanism that give rise to events in the world and our experience of such events. Thirdly, for methodological purposes, analytic dualism is necessary to examine the interplay between structure, culture and agency. Social realism enables exactly that.

The notion of a depth ontology, with the domains of the empirical, actual and real, has enabled this study to move beyond that which is experienced and perceived. While the paper acknowledges that learners and teachers have perceptions of the manner in which teachers express their teacher identities, that is, their "role as effective communicator", the study illuminates both the domain of the actual and the real. With regard to the actual, the paper shows how Nokhaya and Buhle teach mathematics in isiXhosa or isiXhosa and English respectively. The mechanisms at the level of the real (e.g. the Language in Education Policy) condition the expression of the teachers' identities. In this regard, the researcher is then able to consider how the combination of different mechanisms enables or constrains teachers' identities.

Archer's (2000) stratified view of persons offers a more holistic view of agency, often not evident in the aforementioned research. This assumes that teacher agency is emergent from individual's social identities, personal identities and continuous sense of self. Given the brevity of this paper, the relationships between personal and social identities (i.e. teacher identities) have not been explored. Archer's (2000) conception of teacher identities as the expression of their roles as teachers enables researchers to operationalise teacher identity, without giving primacy to language.

The morphogenetic approach provides an explanation that does not render agency a product of structural and cultural mechanisms. Rather, it assists in explaining how agency is conditioned by the social and cultural systems, and how it can contribute to the elaboration or reproduction of these systems. Agency has its own properties and powers (e.g. reflexivity), meaning that it can transform structure, culture and itself in the process. Reflexivity, the ability to deliberate about oneself or one's actions in relation to contexts one finds oneself in, is a personal power and property that enables teachers to "act back" on the mechanism that condition the manner in which they express their role as teachers (Archer, 2007). While Nokhaya chooses to teach in isiXhosa, Buhle's decision to use both isiXhosa and English is a deliberate action based on her internal conversation of how to communicate mathematics clearly and effectively. As such, she "acts back" on the structural and cultural mechanism constraining the manner in which she expresses her role as a teacher.

In identifying the structural and cultural mechanisms that condition teachers' practices, and the manner in which teachers mediate these conditions, we can begin to understand why it is that teachers do what they do. This is important if we wish to assist teachers in shifting their teacher identities. In South Africa, many teachers, despite in-service teacher education opportunities, still express their teacher identities in "traditional" ways that limit opportunities for sense-making in mathematics (Westaway \& Graven 2018). Understanding the underlying conditions that enable and constrain the extent to which teachers express their roles as teachers of primary mathematics, may assist teacher educators in promoting change. 
A limitation of the social realist argument presented in this article is that it privileges the social-cultural over the psychoanalytical perspective on identity.

Danermark, Ekström, Jakobsen and Karlsson (2002) argue, "social science analysis is essentially a matter of using theories and frames of interpretation to gain a deeper knowledge of social meanings, structures and mechanisms. In this way we build up knowledge that cannot be reduced to empirical facts" (p. 92). While this paper is largely theoretical, it has drawn on data of two primary school teachers, to demonstrate what social realism enables; that is, it has foregrounded that which is not illuminated in research underpinned by a social constructionist orientation.

The argument made in this paper elucidates how social realism supports a deep analysis of the structural, cultural and agential conditions that enable and constrain teacher identity. Social realism thus assists in answering different research questions; that is, research questions that are not answerable in research underpinned by a social constructionist orientation. We thus suggest that social realism has much to offer mathematics education research on teacher identity.

Open Access This article is distributed under the terms of the Creative Commons Attribution 4.0 International License (http://creativecommons.org/licenses/by/4.0/), which permits unrestricted use, distribution, and reproduction in any medium, provided you give appropriate credit to the original author(s) and the source, provide a link to the Creative Commons license, and indicate if changes were made.

\section{References}

Alexander, N. (2013). Thoughts on the new South Africa. Johannesburg: Jacana.

Archer, M. S. (1995). Realist social theory: The morphogenetic approach. Cambridge: Cambridge University Press.

Archer, M. S. (1996). Culture and agency: The place of culture in social theory. Cambridge: Cambridge University Press.

Archer, M. S. (2000). Being human: The problem of agency. Cambridge: Cambridge University Press.

Archer, M. S. (2007). Realism and the problem of agency. Journal of Critical Realism, 9(2), 11-20.

Berger, P. L., \& Luckman, T. (1966). The social construction of reality: A treatise in the sociology of knowledge. New York: Anchor Books.

Bernstein, B. (2000). Pedagogy, symbolic control and identity: Theory, research, critique (revised ed. London: Taylor and Francis.

Bhaskar, R. (2008). A realist theory of science (4th ed.). London: Verso.

Burridge, P. (2010). Investigating praxis inquiry within teacher education using Giddens's structuration theory. The Journal of Experimental Education, 33(1), 19-37. https://doi.org/10.1177/105382591003300103.

Carter, B., \& Sealey, A. (2000). Language, structure and agency: What can realist social theory offer to sociolinguistics. Journal of SocioLinguistics, 4(1), 3-20.

Danermark, B., Ekström, M., Jakobsen, L., \& Karlsson, J. (2002). Explaining society: Critical realism in the social sciences. London: Routledge.

Darragh, L. (2016). Identity research in mathematics education. Educational Studies in Mathematics, 93(1), 19-33. https://doi.org/10.1007/s10649-016-9696-5.

Drake, C., \& Sherin, M. G. (2006). Practicing change: Curriculum adaptation and teacher narrative in the context of mathematics education reform. Curriculum Inquiry, 36(2), 153-187.

Easton, G. (2010). Critical realism in case study research. Industrial Marketing Management, 39, 118-128. https://doi.org/10.1016/j.indmarman.2008.06.004.

Elder-Vass, D. (2008). Searching for realism, structure and agency in actor network theory. British Journal of Sociology, 59(3), 455-473. https://doi.org/10.1111/j.1468-4446.2008.00203.x.

Fleetwood, S. (2014). Bhaskar and critical realism. In P. Adler, P. du Gay, G. Morgan, M. Reed (Eds.), The Oxford handbook of sociology, social theory and organisation studies: contemporary currents (pp.182219). Oxford: Oxford University Press

Foucault, M. (1982). The subject and power. Critical Inquiry, 8(4), 777-795. https://doi.org/10.1086/448181. Giddens, A. (1984). The constitution of society: Outline of the theory of structuration. Cambridge: Polity Press. 
Graven, M. (2003). Teacher learning as changing meaning, practice, community, identity and confidence: the story of Ivan. For the Learning of Mathematics, 23(2), 25-33.

Graven, M. (2012). Changing the story: teacher education through re-authoring their narratives. In C. Day (Ed.), Routledge international handbook of teacher and school development (pp. 127-138). Abingdon: Routledge.

Graven, M., \& Heyd-Metzuyanim (2019). Mathematics identity research: the state of the art and future directions. ZDM, 51(3), 361-377.

Grootenboer, P., \& Ballantyne, J. (2010). Mathematics teachers: Negotiating professional and discipline identities. In L. Sparrow, B. Kissane, \& C. Hurst (Eds.), Shaping the future of mathematics education: Proceedings of the 33rd annual conference of the Mathematics Education Research Group of Australasia (pp. 225-232). Freemantle:MERGA.

Grootenboer, P. J., Smith, T., \& Lowrie, T. (2006). Researching identity in mathematics education: The lay of the land. In P. Grootenboer, R. Zevenbergen, \& M. Chinnappan (Eds.), Identities, cultures and learning spaces Proceedings of the 29th annual conference of mathematics education research Group of Australasia (pp. 612-615). Canberra: MERGA.

Jansen, J. (2001). Image-ining teachers: policy images and teacher identity in South African classrooms. South African Journal of Education, 21(4), 242-246.

Jita, L., \& Vandeyar, S. (2006). The relationship between the mathematics identities of primary school teachers and new curriculum reforms in South Africa. Perspectives in Education, 24(1), 39-52.

Lave, J., \& Wenger, E. (1991). Situated learning: Legitimate peripheral participation. Cambridge: Cambridge University Press.

Lester, F. K. (2005). On the theoretical, conceptual, and philosophical foundations for research in mathematics education. ZDM, 37(6), 457-467. https://doi.org/10.1007/BF02655854.

Lutovac, S., \& Kaasila, R. (2018). Future directions in research on mathematics-related teacher identity. International Journal of Science and Mathematics Education, 16, 759-776. https://doi.org/10.1007 /s10763-017-9796-4.

MacLure, M. (2003). Discourse in educational and social research, Buckingham: Open University Press.

Naidoo, D., \& Parker, D. (2005). The implications of mathematics teachers' identities and official mathematics discourses for democratic access to mathematics. Perspectives in Education, 23(1), 53-67.

Nel, B. (2012). Transformation of teacher identity through a mathematical literacy re-skilling programme. South African Journal of Education, 32, 144-154.

Pausigere, P., \& Graven, M. (2013). Unveiling the South African official primary mathematics teacher pedagogical identity. Perspectives in Education, 31(3), 19-33.

Pausigere, P. (2014). Primary maths teacher learning and identity within a numeracy inservice community of practice (doctoral dissertation). Retrieved from https://www.ru.ac. $\mathrm{za} /$ media/rhodesuniversity/content/sanc/documents/Peter_Pausigere_PhD_final_corrected.pdf .

Phakeng, M., \& Moschkovich, J. (2013). Mathematics education and language diversity: A dialogue across settings. Journal for Research in Mathematics Education, 44(1), 119-128. https://doi.org/10.5951 /jresematheduc.44.1.0119.

Setati, M. (2008). Access to mathematics versus access to the language of power: The struggle in multilingual mathematics classrooms. South African Journal of Education, 28(1), 103-116.

Sfard, A., \& Prusak, A. (2005). Telling identities: In search of an analytic tool for investigating learning as a culturally shaped activity. Educational Researcher, 34, 1422. https://doi.org/10.3102/0013189 X034004014.

South Africa. Department of Education (SA.DoE). (1996). The south African schools' act (act no 84 of 1996). Retrieved on 19 June 2016 from.http://www.education.gov.za/LinkClick.aspx?fileticket=aIolZ6UsZ5 U\%3D\&tabid=767\&mid=3184

South Africa. Department of Education (SA.DoE). (1997). Language in education policy. Retrieved on 13 September 2015 from.http:/www.education.gov.za/Portals/0/Documents/Policies/GET/LanguageEducationPolicy1997. pdf?ver=2007-08-22-083918-000

South Africa. Department of Education (SA.DoE). (2000). Norms and Standards for Educators. Government gazette 20844, notice 415, 4 February (p. 2000). Government Printer: Pretoria.

Wenger, E. (1998). Communities of practice: Learning, meaning an identity. Cambridge: Cambridge University Press.

Westaway, L. (2017). The emergence and expression of teachers' identities in teaching Foundation Phase mathematics. Unpublished Ph.D. thesis, Rhodes University, Grahamstown.

Westaway (2019). The role of reflexivity in the emergence and expression of teachers' identities in teaching primary school mathematics . ZDM, 51(3), 481-492 
Westaway, L. \& Graven, M. (2018). Exploring grade 3 teachers' resistance to 'take up' progressive mathematics teaching roles. Mathematics Education Research Journal, 31(1), 27-46. https://doi.org/10.1007 /s13394-018-0237-7

\section{Affiliations}

\section{Lise Westaway $^{1} \cdot$ Gabriele Kaiser $^{2,3} \cdot$ Mellony Graven $^{1}$}

1 Rhodes University, Grahamstown, 6140, South Africa

2 Universität Hamburg, Faculty of Education, Von-Melle-Park 8, 20146 Hamburg, Germany

3 Institute for Learning Sciences and Teacher Education, Australian Catholic University, Melbourne, Australia 